\title{
Use of web 2.0 technologies by library and information science students
}

Colin Zinyeredzi and Sandy Zinn

\begin{abstract}
The research reported on in this article investigated the use of Web 2.0 technologies by library and information science (LIS) students at the University of the Western Cape (UWC), South Africa. Blumer and Katz's Uses and Gratification Theory, which explains the reasons behind people's use of Web 2.0 technologies, was used to provide meaning to the research findings. A case study approach was used to collect data by means of a questionnaire, content analysis and interviews. The findings revealed that between 72 and 97 per cent of LIS students have accounts on the following Web 2.0 technologies: YouTube, Skype, Google Apps, WhatsApp, Twitter and Facebook. In a nutshell, the research threw light on the Web 2.o technologies used the most by LIS students and also highlighted their reasons for using them. The benefits or gratifications derived from using Web 2.0 technologies were also a highlight of the research. More importantly, the research demonstrated the need to embed Web 2.0 technologies in the LIS curriculum and to encourage academics to continuously embrace emerging technologies.
\end{abstract}

\section{INTRODUCTION}

The purpose of the current research was to investigate the use of Web 2.0 technologies by library and information science (LIS) students at the University of the Western Cape (UWC), South Africa. Web 2.0 refers generally to Web tools that, rather than serve as a forum for experts to impart information to a passive, receptive audience, actually allow site visitors to comment and edit information and as a result bridge the gap between authors and recipients (Garoufallou and Charitopoulou 2011, 491). Web 2.0 encompasses so many new technologies which can be used for a variety of undertakings, among others, social bookmarking, calendaring, collaborative authoring, video sharing, social networking, file and image sharing as well as communication and discussion forums. As new technologies emerge, there is a great need to train LIS students in the use of Web 2.0 technologies owing to the nature of their various work environments, which are predominantly characterised by the dissemination of information.

\section{BACKGROUND AND MOTIVATION}

The world continues to change due to the explosion of and easy access to information as well as continuous development in technology access and integration. Important questions are being raised in LIS programmes with regard to the direction to take in preparing 
students for such a constantly changing future (Chow, Shaw and Gwynn 2011, 2). Chu (2006, 328) concludes that it is inarguable that development in current society, technological or otherwise, has brought significant changes to LIS education all over the world. The LIS curricula mirror the skills and knowledge of the library and information professionals in the workplace.

It is widely recognised that in the unfolding knowledge society, information and knowledge are at the heart of development and economic growth and that the flow of information is critical for innovation, invention and the process of creating new knowledge and ideas (UCT 2013). LIS education, through teaching, continuing education and research programmes, is of paramount importance in providing LIS students with the requisite knowledge and skills to achieve the goals of the LIS sector in an evolving and technologically oriented knowledge society. According to Bawden et al. $(2007,16)$, LIS curricula around the world are rapidly changing owing to recognition of the importance of Web 2.0 in terms of three main facets in teaching and learning activities, namely:

- developments in technology;

- $\quad$ social use/impacts; and

- implications for the field and the profession.

Apart from market demand, LIS curricula around the world are influenced by internationally recognised library associations, for example, the American Library

Association (ALA 2013) and the International Federation of Library Associations and Institutions (IFLA 2012).

\section{LITERATURE REVIEW}

The literature for review was selected in the following way: firstly, the scholarly literature explaining Web 2.0 technologies was addressed; followed by an examination of the current LIS curricula and education; and finally, the literature describing the incorporation of Web 2.0 in LIS education was explored.

\subsection{Web 2.0 technologies}

The world of information is in a state of constant change. How people access, use and benefit from information in such an increasingly hyper-connected world, has become a concern. The first phase of Web technologies, known as the read-only Web, emerged as a platform for oneway communication between information producers and information consumers (Sarrafzadeh, Hazeri and Alavi 2011, 178). From the mid-1990s to the early 2000s, the internet remained fairly one way with primary offerings including informational and transactional, for example, online shopping and reading news articles, among others. Web 1.0 refers to the first stage in the World Wide Web (WWW or the Web), which was entirely made up of Web pages connected by hyperlinks. It is a term that also describes the Web when it was a set of static websites that were not providing interactive content. Mishra (2009) points out that the second generation of the internet came about in the early 2000 s and was 
called Web 2.0 or the Social Web. Web 2.0, also known as the read-write/interactive Web, was crafted to provide the possibility for customers to contribute to the creation of Web content (Maloney 2007, 39).

Web 2.0 harnesses the Web in a more interactive and collaborative manner, emphasising peer social interaction and collective intelligence, and it also presents new opportunities for leveraging the Web and engaging its users more effectively. Web 2.0 is the term coined to describe a multitude of websites and applications that allow anyone to create and share online information or material they have created. A crucial component of the technology lies in its ability to empower people to create, share, collaborate and communicate. The above notion was made by Virkus $(2008,263)$ when he noted that Web 2.0 tools and services foster new modes of connectivity, communication, collaboration, sharing of information, content development and social organisation. Web users are prolific creators of content, and they upload photographs, audio clips and videos to the cloud by the billions (NMC Horizon Report 2014, 8).

Web 2.0 is not solely a technology but offers many more possibilities. Murugesan $(\mathbf{2 0 0 7 , 3 4 )}$ views Web 2.0 not just as a new version of the same old Web; it is different from Web 1.0 in several ways. For example, Web 2.0:

1. facilitates Web design, creative reuse, and updates;

2. provides a rich, responsive user interface;

3. facilitates collaborative content creation and modification;

4. enables the creation of new applications by reusing and combining different applications on the Web or by combining data and information from different sources;

5. establishes social networks of people with common interests; and

6. supports collaboration and helps gather collective intelligence.

There are various categories of Web 2.0 technologies, such as: social bookmarking (e.g. StumbleUpon, Delicious, CiteULike); calendaring (e.g. Google calendar); collaborative authoring (e.g. Wikis, Google docs); video sharing (e.g. YouTube, WhatsApp); social networking (e.g. Facebook, WhatsApp, Twitter, Pinterest, Flickr, YouTube, Tumblr, Instagram); and file sharing and communication tools (e.g. Napster, 4shared, Webshots). The abundance of Web 2.0 technologies necessitates an examination of LIS education to establish whether it is considered significant enough to be incorporated into curricula.

\subsection{LIS education and curricula}

The information world in which LIS students are studying and are being educated is continuously changing owing to a variety of reasons (Aharony 2009, 227). On the one hand, LIS is dedicated to understanding the nature of the information world as well as the interaction between information and communication technologies (ICTs) (Tumuhairwe $2013,2)$. On the other hand, it is dedicated to understanding the relationship between information and knowledge; the cognitive and affective aspects of knowledge acquisition; 
and the interface between people and information. LIS education faces considerable opportunities and challenges in the twenty-first century. LIS schools must produce information specialists who are in a position to respond flexibly to rapidly evolving social, economic and technological change (Combes, Hanisch and Carroll 2011, 1).

Wolske (2013) is of the opinion that LIS education is faced with an array of issues, among others, preparing LIS students for new roles in a rapidly changing job market; offering student-centred educational opportunities through service learning; enabling conceptual understandings of ICT that prepare students to adapt and utilise whatever emerges tomorrow; and developing curricula that will sensitise future librarians to the diverse populations served by libraries. The LIS academic curriculum has been a matter of discussion worldwide as LIS schools have embraced information studies and sought to determine the fundamental changes useful to the profession (Nagatsuka, Tsunoda and Harada 2013).

Curriculum content is at the centre of the reform, and often LIS schools and departments update their curricula in such a way that irrelevant courses disappear to pave the way for emerging issues and trends (Tumuhairwe 2013, 1). In most cases, LIS training has been reconceptualised and repositioned to produce graduates with the appropriate skills to maintain high quality professional practice in the ever-changing twenty-first century. In their study, Bawden et al. $(2007,18)$ compared LIS curricula in five countries: Australia, Ireland, Lithuania, Slovenia and the United Kingdom (UK). They reported changes in the curriculum content as well as pedagogy. Their thematic analysis showed an increasing proportion of e-content and the impact of the communication and social networking features of Web 2.0 and Library 2.0 technologies.

LIS schools in South Africa, like in many other parts of the world, are part of a "triangular relationship" involving LIS teaching departments, universities and the library and information services profession (Raju 2013, 250). Most LIS schools in South Africa are located in universities, which ensures that their curriculum development and quality control are adequately monitored and evaluated. This is despite and in addition to the presence of the national qualification authorities, such as the South African Qualifications Authority (SAQA) (Ocholla and Bothma 2007, 149). However, an agreement seems to exist amongst various authors that LIS curricula need to be tailor-made to include the broader concept of Web 2.0 technologies and all their facets. LIS students as future information professionals need to be aware of the issues and innovations around Web 2.0 technologies more than students from different departments, for example, Psychology (Bawden et al. 2007, 16). According to the South African Library and Information Services Transformation Charter (DAC and NCLIS 2014), librarians need to be thoroughly versed in the application of ICTs in library operations in a bid to serve their patrons' digital needs better. The next section details how LIS education and training has embraced Web 2.o.

\subsection{Web 2.o technologies for LIS education}

As the librarian profession advances to meet the needs of its era, using Web 2.0 technologies has become an indispensable tool in the work of the professional. There is no 
doubt that Web 2.o technologies have changed and transformed access to information and communication. Web 2.0 technologies offer user-created content platform applications which allow users to contribute their knowledge in different formats, for example, text, data, video and audio (Al-Daihani 2009, 39). The creation of the term "Web 2.0" generated other related terms, such as Library 2.0, and Learning 2.0 (Garoufallou and Charitopoulou 2011, 492). These terms reflect the implementation of Web 2.0 technologies in different domains (Al-Daihani 2009, 39; Sawant 2012, 11). In other words, the term "Library 2.0" generally refers to the introduction of Web 2.0 technology tools in library services.

The development of Web 2.0 technologies has presented new opportunities and challenges to education and educational systems of different disciplines including LIS (Al-Daihani 2009, 40; Garoufallou and Charitopoulou 2011, 491; Sarrafzadeh et al.

2011, 179). Many higher education institutions (HEIs) have a history of using ICTs in teaching and learning. According to the NMC Horizon Report $(2014,8)$, for HEIs, social media enables two-way dialogues between students, prospective students, educators, and the institution that are less formal than with other media. With the continued growth of social networks, educators are using them as professional communities of practice, platforms of learning, and as spaces for sharing interesting stories about topics covered in class. Understanding how social media can be embraced and deployed for social learning is a key skill for educators, and teacher training courses are increasingly expected to cater for this skill. However, it is important to note that technology alone does not mean success in any context. Virkus $(2008,272)$ makes it clear that technology only becomes valuable in education if learners and educators can reap positive benefits out of it.

Sarrafzadeh et al. (2011, 178) maintain that the need for LIS students to familiarise themselves with Web 2.0 technologies has been reinforced in recent years. Preparing LIS graduates for the emerging Library 2.0 environment; reaping the educational benefits that Web 2.0 tools offer; and meeting the needs of the so-called net generation are some of the reasons for supporting the idea of using Web 2.0 technologies in LIS education and incorporating its related themes into the LIS curriculum. Al-Daihani $(2009,42)$ highlights that the increasing use of Web 2.0 technologies in the field of LIS makes it incumbent upon the educational programmes to respond to the challenges and demands of the technology.

Virkus $(2008,272)$ points out that the use of Web 2.0 technologies is more beneficial for LIS education than any other discipline because LIS students will utilise Web 2.0 tools in their day-to-day work. For LIS trainees and professionals, as explained by Virkus (2008, 270), Web 2.o is not only about technology, it also means significant attitudinal shifts in the profession. Today's society is built on a digital environment of work, hence it is imperative for LIS students to be trained in the use of Web 2.0 technologies as this will better place them to meet the challenges of the work environment.

The need for a holistic approach to embed Web 2.0 applications in LIS education is emphasised in the literature. Issues around Web 2.0 technologies, as explained by 
Sarrafzadeh et al. (2011, 179), are not only required to be an integral part of the LIS curriculum, but should also be applied in the structure of the educational context to support both LIS teaching and learning. As a result, it is imperative for the LIS education system to foster the actual engagement of learners with the new environment in the learning process. The integration of Web 2.0 technologies with LIS teaching and learning environments also offers a great chance for LIS students to be prepared for lifelong learning (Sarrafzadeh et al. 2011, 180).

\section{THEORETICAL FRAMEWORK}

Web 2.0 incorporates a variety of meanings, including an increased emphasis on user generated content, data, content sharing and collaborative effort together with the use of various kinds of social software and new ways of interacting with web-based applications (Harris and Rea 2010, 137). Most of the emerging Web 2.0 services, as explained by Shao (2009), are relatively easy to use and together constitute the only media that can instantaneously provide the potential for one-to-many and many-to- many synchronous communications. With the sheer number of media choices available to individuals today, it is important to ascertain the appeal of certain media and why consumers choose one medium and disregard others. This can be easily understood when examined through the lens of a theoretical framework. One theory that emerged in 1974 from Blumer and Katz examines media consumption by how it is consumed and what benefits it creates for the consumer. This framework, which has come to be known as the Uses and Gratifications Theory (UGT) has been repeatedly tested and improved over the years.

The UGT is applied to understand media usage. It is concerned with how and why people turn to the media they do. Eighmey and McCord (1998) found in their study of uses and gratifications in relation to the internet that factors associated with entertainment, personal relevance, ease of use and information seeking were reported most often. Uses in the theory can be defined as how people choose and interact with media; whereas gratifications can be defined as the reasons behind users choosing a particular medium and the benefits they derive from the chosen medium. Shao (2009,

9) summarises common reasons for media consumption: "information seeking, to pass time, relaxation, communication utility, integration and social interaction as well as entertainment". It was against this background that the researchers ascertained the reasons why LIS students use Web 2.0 technologies.

\subsection{Consumption for information and entertainment}

As with traditional media and entertainment, individuals can go to user-generated sites to consume content, such as video clips, blogs, pictures and music (Theimer 2010). The question is why individuals choose to consume user-generated content and what gratifications they expect to gain from such consumption. Previous UGT research on traditional and new media has revealed two typical motives for media consumption, namely, information seeking and entertainment. This can help to understand people's media consumption of user-generated media. More importantly, this helps to explain why LIS students use Web 2.0 technologies which are entirely user-generated sites. 
Information seeking is driven by people's desire to increase awareness and knowledge of their self, others and the world (Shao 2009, 9).

Shao $(2009,10)$ and Garoufallou and Charitopoulou $(2011,495)$ made it clear that people increasingly make use of Facebook, YouTube, and other social media to learn how to make sense of things from their peers on just about any subject. Compared with information seeking, entertainment may be more important in triggering media use.

Ruggiero's $(2000,35)$ viewpoint is that most people see entertainment and mass media

as nearly synonymous. It was important to understand what triggers LIS students to use user-generated media, whether for information seeking or entertainment as seen through the lens of the UGT.

\subsection{Participating for social interaction}

In addition to consuming content, people may participate through interacting with the content as well as with other users on user-generated sites (Maloney 2007; Mishra 2009). User-to-content interaction occurs when people rate content, save it to their favourites, share it with others, post comments, and so on (Shao 2009, 12). On the other hand, userto-user interaction occurs when people interact with each other through email, instant messages (e.g. WhatsApp, chat rooms, message boards, other internet avenues) (Covili 2012; Garoufallou and Charitopoulou 2012; Theimer 2010). Since its inception, the internet has become a prime venue for social interaction. Ruggiero (2000, 29) explains that major internet websites, such as Gmail and Yahoo, provide a number of electronic avenues (e.g. e-mail, chat rooms, message boards) through which people can communicate with others, and share their interests and values. The birth of user- generated sites has accelerated this trend, as shown in LinkedIn, Facebook, and many other social sites which are rooted in meeting people's social interaction needs. Further than social interaction, users may also contribute to the formation and maintenance of virtual communities on usergenerated sites. The current research provides answers to whether LIS students use Web 2.0 technologies for interaction.

Ruggiero (2000) highlights the necessity of the UGT in understanding the proliferation and success of computer-mediated communication forms. The UGT provides a cutting-edge theoretical approach in the initial stages of each new mass communication medium: newspapers, radio and television, and now the internet (Ruggiero 2000, 29-33). The primary question to ask is: "Do LIS students use Web 2.0 technologies for information seeking, to pass time, for relaxation, as a communication utility, for integration and social interaction, or as a source of entertainment?" This can best be understood when looked at through the lens of the UGT.

\section{RESEARCH QUESTIONS}

The study investigated the use of Web 2.0 technologies by LIS students at UWC. The UGT assumes that audiences deliberately choose the medium that could fulfil their needs and that they are able to recognise their reason for making media choices (Shao 2009, 9). The

results from existing UGT research suggest that people use media either for content carried 
by the medium (e.g. information or entertainment), or for the simple experience of the media usage process (e.g. playing with the technology) (Stafford and Schkade 2004, 267). The UGT provides a deeper insight into why LIS students use Web 2.0 technologies in general and in the academic context. The study provided answers to the following research questions:

1. Which Web 2.0 technologies are used mostly by LIS students?

2. What do LIS students use Web 2.0 technologies for?

3. How is the LIS curriculum crafted to include training in Web 2.o technologies?

4. What benefits (gratifications) do LIS students derive from the use of Web 2.0 technologies?

5. Which Web 2.o technologies are LIS students being taught?

\section{RESEARCH DESIGN AND METHODOLOGY}

In South Africa, there are 10 LIS departments located within academic universities, namely: the University of Cape Town; the University of Fort Hare; the University of KwaZulu-Natal; the University of Limpopo; the University of Pretoria; the University of South Africa; the University of the Western Cape; the University of Zululand; Walter Sisulu University; and the Durban University of Technology (Ocholla and Bothma 2007, 150). The research was limited to the UWC LIS Department, which is one of two LIS schools in the Western Cape. The UWC LIS Department offers a four-year Bachelor of Library and Information Studies (BLIS) degree; a Postgraduate Diploma in Library and Information Studies (PGDipLIS); a master's (MLIS) degree; and a PhD degree. The department has a niche in public and school librarianship although it also educates students for academic and special libraries (UWC, Department of Library and Information Science 2015).

Answers to the research questions were explored through the use of a case study. The main objective of the research was to provide a deep understanding of Web 2.0 technology use by LIS students and to ascertain if the curriculum is designed to include Web 2.0 aspects. A questionnaire characterised by both open-ended and closed-ended questions was administered to LIS students. The questionnaire was divided into five sections: Section A gathered background data about the respondents and their programmes (level). Section B gathered data about the familiarity of the respondents with Web 2.0 technologies. It also collected data about where students normally access Web 2.0 tools (geographical location) as well as the devices they use to access Web 2.0 technologies. Section C gathered data about the use of Web 2.0 technologies, firstly looking at what they use Web 2.o technologies for in general, and secondly, what they use Web 2.0 technologies for in the academic spheres, and lastly how often they use Web 2.0 technologies. Section D probed the benefits associated with the use of Web

2.o technologies. Finally, Section E gathered data about Web 2.o technology education. Semi-structured interviews were conducted face-to-face with the lecturers of the UWC LIS Department, who were the key informants owing to their in-depth knowledge about the curriculum. The departmental websites, course outlines, assignment topics and curriculum 
documents were analysed to identify modules that include Web 2.0 aspects. The data collected from the questionnaires, interviews and content analysis was triangulated.

\subsection{Study participants}

The research used a purposive sample of students in the UWC LIS Department. A total of 144 students were participants, of whom 112 were in the BLIS programme; 18 were in the MLIS programme; 11 were in the PGDipLIS programme; and three were in the PhD programme. Six academics in the LIS Department were chosen as key informants. Of the six interviewed academics, one was an associate professor; two were senior lecturers; and the others were lecturers.

\section{RESULTS AND DISCUSSION}

The data collected from the questionnaires, interviews and content analysis was analysed and triangulated. Blumer and Katz's $(1974,76)$ UGT, as applied by Ruggiero (2000) and Shao (2009) to modern media, was used to interpret the results.

\subsection{Web 2.0 technologies used the most by LIS students}

The study results revealed that more than 72 per cent of the LIS students have accounts on the following Web 2.o sites: YouTube, Skype, Google Apps, WhatsApp, Twitter and Facebook; and 96.3 per cent of them have an account on Facebook. The latter result, highlighting the high usage of Facebook amongst students, concurs with the findings of Barnet, Collis and Narborough (2010, 7), who, in a similar study at Loughborough University in the UK, discovered that 96 per cent of the students use Facebook. Thus, the research findings align with those of a similar study by the World Wide Worx and Student Brands (2013) in South Africa, which clearly demonstrated that Facebook is the universal social networking site for students with 96 per cent of the respondents using it, while Twitter is used by 70 per cent.

As explained by Zaremohzzabieh, Abu and Omar (2014, 107), Facebook has become an essential part of almost every university student's daily life, and a large number of students seem to derive benefits from using Facebook to exchange information for educational goals; to make friends; and for other activities. Facebook is one of the most popularly accessed social networks and has over 500 million registered users; hence, it has the potential to become an ally in the teaching and learning process. If properly used, "Facebook allows the formation of groups with common interests, enables the exchange of information, and stimulates the search for knowledge" (De Vargas, De Lara and Gonçalves 2014, 273).

LIS academics in the study recommended that students use Web 2.0 technologies, such as YouTube, Twitter and Google Apps, to accomplish academic tasks/assignments as discovered during content analysis and key informant interviews. This plays a part in students adopting Web 2.o technologies. An analysis of the curriculum documents showed that the ICT Trends and Applications module requires postgraduate students to reflect on their lectures every week and tweet their reflections as well as comment on tweets sent by fellow students. 
Regarding the use of YouTube and Google Apps in the classroom, two of the LIS academics pointed out:

I use YouTube extensively because it brings different voices to the classroom and it goes beyond the classroom. (Interviewee 4) I encourage students to use Google drive all the time to share information hence it is a safe way of storing important documents to avoid losing them and viruses. (Interviewee 2)

\subsection{Frequency of using Web 2.0 technologies}

This question probed how often LIS students use Web 2.0 technologies. As depicted in Table 1, more than 60 per cent of the respondents pointed out that they use Facebook, WhatsApp, and Google Apps many times a day.

Table 1: Frequency of using Web 2.0 technologies

\begin{tabular}{|l|l|l|l|l|l|l|}
\hline \multicolumn{7}{|l|}{ Frequency of use } \\
\hline $\begin{array}{l}\text { Web 2.0 } \\
\text { technology }\end{array}$ & $\begin{array}{l}\text { Many times } \\
\text { a day }\end{array}$ & $\begin{array}{l}\text { Once a } \\
\text { day }\end{array}$ & $\begin{array}{l}\text { Many times } \\
\text { a week }\end{array}$ & $\begin{array}{l}\text { Once a } \\
\text { week }\end{array}$ & $\begin{array}{l}\text { Once a } \\
\text { month }\end{array}$ & Never \\
\hline Facebook & $69.6 \%$ & $12.4 \%$ & $10.8 \%$ & $3.6 \%$ & $2.4 \%$ & $1.2 \%$ \\
\hline Twitter & $10.8 \%$ & $3.6 \%$ & $20.5 \%$ & $55.4 \%$ & $7.3 \%$ & $2.4 \%$ \\
\hline Linkedln & $1.2 \%$ & $3.6 \%$ & $6 \%$ & $10.8 \%$ & $14.5 \%$ & $63.9 \%$ \\
\hline WhatsApp & $65.1 \%$ & $0 \%$ & $32.5 \%$ & $1.2 \%$ & $0 \%$ & $1.2 \%$ \\
\hline Blog & $1.2 \%$ & $3.6 \%$ & $6 \%$ & $10.8 \%$ & $14.5 \%$ & $63.9 \%$ \\
\hline YouTube & $16.9 \%$ & $25.3 \%$ & $53 \%$ & $3.6 \%$ & $1.2 \%$ & $0 \%$ \\
\hline Skype & $8.4 \%$ & $9.6 \%$ & $15.7 \%$ & $16.9 \%$ & $30.1 \%$ & $19.3 \%$ \\
\hline Dropbox & $7.2 \%$ & $7.2 \%$ & $11 \%$ & $4.8 \%$ & $8.4 \%$ & $61.4 \%$ \\
\hline Flickr & $0 \%$ & $1.2 \%$ & $9.7 \%$ & $8.4 \%$ & $19.3 \%$ & $61.4 \%$ \\
\hline Viber & $4.8 \%$ & $6 \%$ & $8.5 \%$ & $2.4 \%$ & $7.2 \%$ & $71.1 \%$ \\
\hline Delicious & $0 \%$ & $3.6 \%$ & $2.5 \%$ & $3.6 \%$ & $9.6 \%$ & $80.7 \%$ \\
\hline Podcast & $1.2 \%$ & $3.6 \%$ & $6 \%$ & $9.6 \%$ & $6 \%$ & $73.6 \%$ \\
\hline Google Apps & $62.9 \%$ & $7.2 \%$ & $21.5 \%$ & $4.8 \%$ & $2.4 \%$ & $1.2 \%$ \\
\hline RSS feeds & $4.8 \%$ & $2.4 \%$ & $3.6 \%$ & $4.8 \%$ & $24.8 \%$ & $59.6 \%$ \\
\hline Wiki & $7.2 \%$ & $10.8 \%$ & $8.4 \%$ & $15.7 \%$ & $53.1 \%$ & $4.8 \%$ \\
\hline
\end{tabular}

Over 50 per cent of the LIS students use Twitter and YouTube on a weekly basis. Therefore, it can be concluded that the LIS students use YouTube, Google Apps, WhatsApp, Twitter and Facebook the most. A similar study in Greece by Garoufallou and Charitopoulou $(2011,494)$ found that Facebook, followed by YouTube, were the leading Web 2.0 sites used by Greek LIS students. The high usage of Facebook followed by WhatsApp can be understood when looked at through the lens of Blumer and Katz's (1974) 
UGT. The UGT highlights passing time, entertainment, relaxing and perceived ease of use as some of the reasons people would prefer to use specific Web 2.0 technologies.

\subsection{Purpose for using Web 2.o technologies}

The participants were probed about their purpose for using Web 2.0 technologies. In as far as the general use of Web 2.0 technologies is concerned, over 80 per cent of the LIS students use Web 2.o technologies for entertainment, keeping up-to-date, and meeting people as well as for communicating with peers and lecturers (see Figure 1).

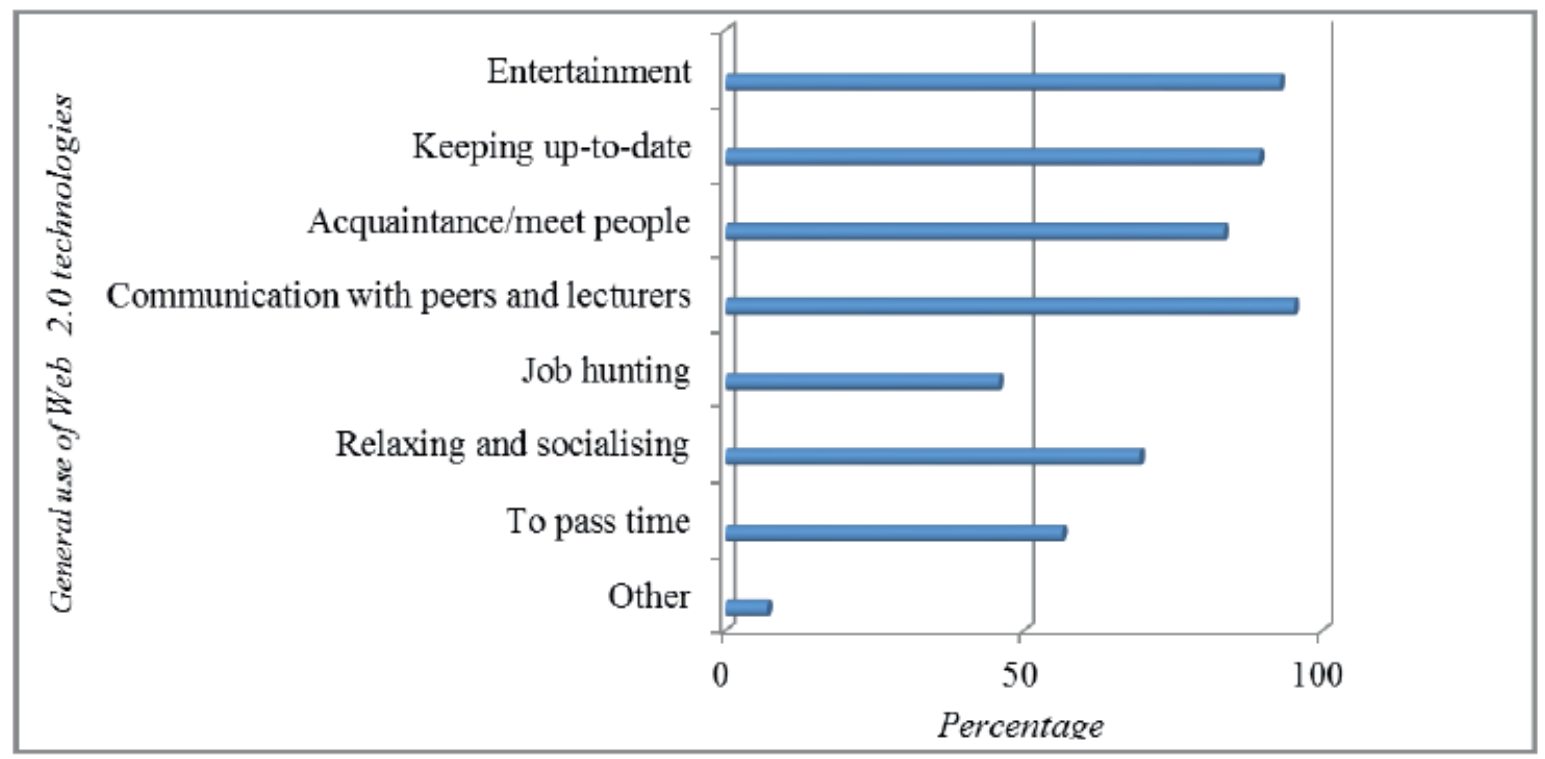

Figure 1: Use of Web 2.0 technologies for general purposes

The LIS students also use Web 2.0 technologies for academic purposes. The study results showed that the LIS students use Web 2.0 technologies academically for knowledge sharing with fellow students (96\%); collaborative authoring (67\%); communicating with peers and lecturers (96\%); information seeking/research (97\%); assignments (76\%); as well as to remain abreast of technology (76\%) (see Figure 2). 


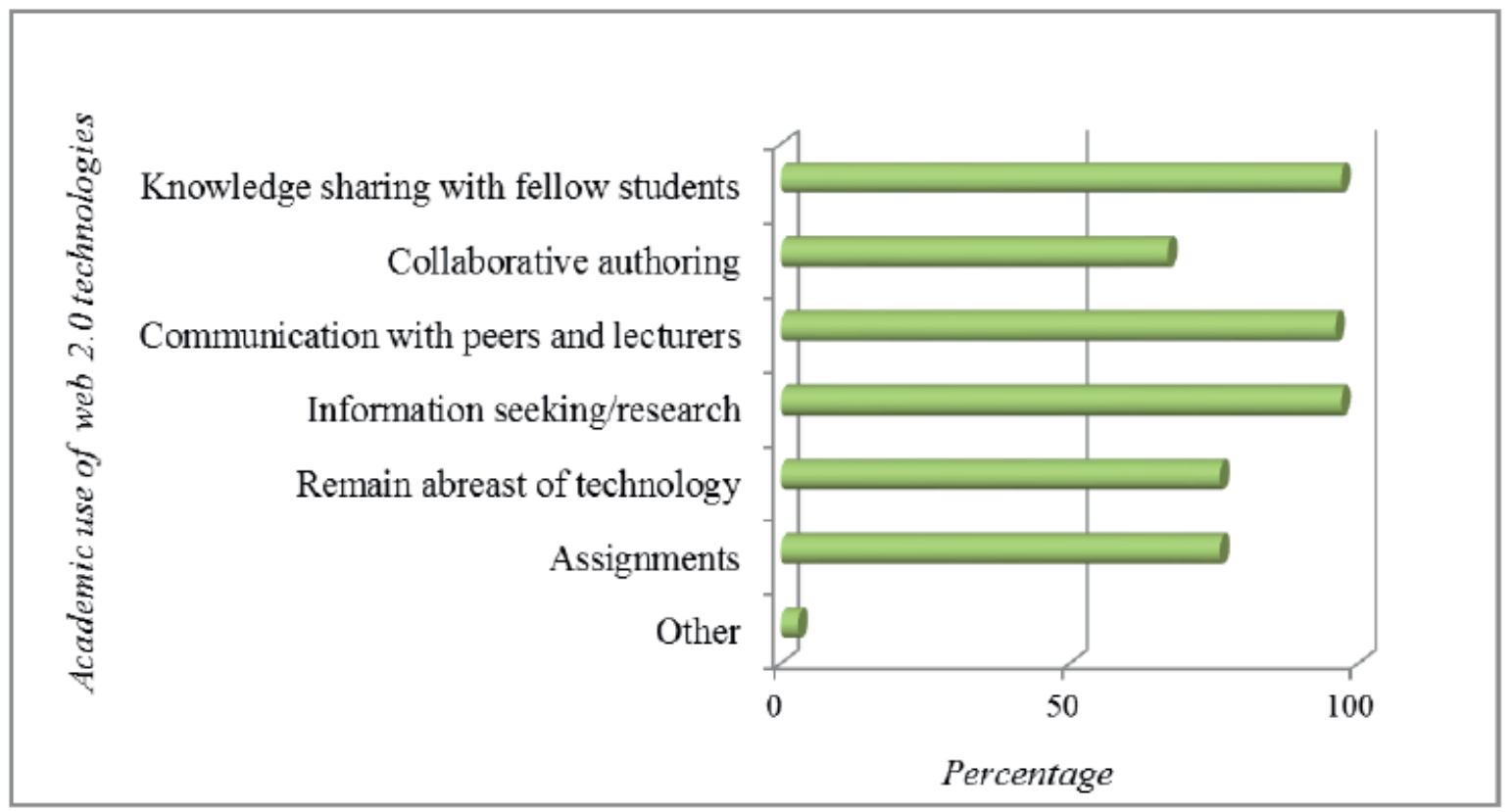

Figure 2: Use of Web 2.0 technologies for academic purposes

A similar study conducted by Matingwini (2014, 66) in Zimbabwe found that the majority of the students (75\%) indicated that they had used Web 2.0 tools to search for scholarly information; 71 per cent used the tools for communication; 64 per cent used them for sharing files; and 46 per cent received course materials from lecturers using the tools.

An analysis of the curriculum documents revealed academic assignments where students are required to collaborate on projects using Web 2.0 technologies, for example, using Google Apps and wikis. Collaboration entails that the students have to communicate with each other and this is best achieved efficiently, quickly and cheaply through the use of Web 2.o technologies like WhatsApp, Google-talk group chats or Skype. Interviews with the key informants revealed that indeed LIS students use Web 2.0 technologies for both general and academic purposes. The following are extracts from the interviews highlighting both academic and general reasons for use of Web 2.0 technologies by the LIS students:

Students use Web 2.0 for socialising, making friends, entertainment, academics (Research) and communication because it is cheaper. (Interviewee 4)

They use it in a personal capacity, for example, Facebook and Twitter to chat with friends, and downloading songs on YouTube. (Interviewee 5)

They use it for both personal and academic purposes, some use it to access the catalogue and search for journals. They also use it for communication with peers. (Interviewee 2) Students use Google drive to analyse data and it makes the research methods course easier, it makes sharing information and knowledge easier and seamless. (Interviewee 3)

Web 2.0 is evident in an emerging suite of applications that are interactive, context-rich, and easy to use. The explosion of user-generated content on the internet points to the 
immense potential of Web 2.0 technologies in enriching communication, enabling collaboration, and fostering innovation on an extraordinary scale (Chua and Goh 2010, 203).

\subsection{Inclusion of Web 2.0 instruction in the LIS curriculum}

The curriculum and pedagogy of LIS education need to transform in order to meet new expectations in the twenty-first century. Many researchers, as highlighted by Noh, Ahn and Choi (2012, 349), have argued that LIS curricula need to be changed and new courses created to reflect the changes in libraries and information centres. Studies encouraging changes in curriculum start from the rationality that curricula should be changed constantly to produce future librarians who can adapt to changes in the external environment as the library environment changes rapidly due to information technology development, among other factors (Noh et al. 2012, 349-350).

The same sentiments are echoed by Srivastava $(2009,375)$ who suggests that library schools have to undergo the rigorous work of curriculum revision periodically and in the process try to maintain pace with technological innovations. Higher education, according to Hicks and Graber (2010), "needs to adapt to the new realities that inform key areas of their work. Information realities and student realities have changed considerably and it is important that the shifts technology brings are fully understood".

Analysis of the curriculum documents and assignments as well as interviews with key informants in the present study revealed that, while a module entitled "Web 2.0" does not exist, elements of Web 2.0 technologies are embedded in some of the LIS modules. Analysed curriculum documents showed that the following BLIS modules have aspects of Web 2.0 embedded in them: LIB 121: Information literacy; INF 411: ICT applications in LIS; and INF 412: World Wide Web. The ICT Trends and Applications in LIS is one of the modules where Web 2.0 aspects are embedded in both the PGDipLIS and MLIS. The following Web 2.0 technologies are predominantly mentioned in the LIS curriculum: Really Simple Syndication (RSS), Twitter, weblogs, wikis, and YouTube. Students at both undergraduate and postgraduate level are required to accomplish several assignments/projects using prescribed Web 2.o technologies, for example, MLIS students are required to create a wiki, a Twitter account and a blog in the ICT Trends and Applications in LIS module.

Interviewees 1 and 5 indicated that there are no specific Web 2.0 technologies taught to students but they are rather used to support learning and sharing knowledge and information and as a result students would learn to use them in order to accomplish specific assignments. This assertion was similar to the sentiment echoed by Interviewee 2, who explained the incorporation of Web 2.0 technologies in the various LIS programmes.

Courses where Web 2.0 have been incorporated include: ICT application at Undergraduate, Post graduate diploma and at Master's levels. This course has changed over time because of the changes in technology. There is a need to keep up the pace. In the ICT applications 
module, students are taught Web 2.0 technologies use and how they can be applied in libraries.

Of the six interviewed academics, five agreed to the inclusion of Web 2.0 technologies in the LIS curriculum. Below are their expressed reasons:

Technological issues cannot be avoided because it is there and has to be incorporated into the courses offered. E-books, mobile technology, tablet computing are issues we cannot ignore. The Horizon; Trend reports and so on, are all talking about the same issues and there is no way they can be ignored. Digital curation is a big wave coming because of the demand in research. (Interviewee 2)

Web 2.0 technologies should be incorporated in the curriculum, not as a separate module but should be infused in all modules. (Interviewee 3)

Students would like to see Web 2.o technologies incorporated in their learning. (Interviewee 5 ) There is a lot of value in the use of Web 2.0 technologies as long as one fully understands ithence it should be included. It also paints a good picture on the profession. (Interviewee 6) Web 2.0 technologies should be incorporated in the curriculum, not as a separate module but should be infused in all modules, for example, teaching marketing and communication one has to make use of emerging technologies. (Interviewee 3)

Web 2.0, as highlighted by one of the interviewees,

... should be incorporated in the curriculum only if it advances the interests of the profession and take it forward as well as enhance it, that is, if it improves service delivery.

However, Interviewee 1 did not wholly subscribe to the notion of Web 2.0 being important for the LIS curriculum and saw LIS schools as drifting away from "core/ primary" professional issues being attracted by "funky issues" like Web 2.o technologies. This assertion is contrary to the findings of the online questionnaire where LIS students were asked if they thought that Web 2.0 technologies should be included in the LIS curriculum. Of the respondents, eighty-one (95.3\%) would like Web 2.0 technologies to be included in the curriculum and only four (4.7\%) share the same sentiments with one of the academics to not prioritise Web 2.0 for the LIS curriculum.

Well-articulated reasons gathered from the questionnaire supporting the inclusion of Web 2.0 technologies by LIS students included that,

since technology is ever changing and we are studying LIS, we will work with information. It is very important for us to know about the latest technology and how to use it and the LIS programme is perfect to teach us about Web 2.0 and modern technology has made it essential for librarians to be skilled in Web 2.0 technologies. 
The advent of the internet, knowledge management, Web 2.0 and Library 2.0 through the 1990 and 2000 s has indeed posed significant challenges for library schools to keep pace with the changes (Foo and $\mathrm{Ng}$ 2008). Some studies, for example by Bawden et al.

(2007) and Foo and Ng (2008), found that LIS curricula have started to adopt either a specific course on Web 2.0 or on issues related to Web 2.0, such as wikis, blogs, Flickr, social bookmarks and social networking.

Web 2.o technologies, such as blogs, wikis, and the use of social networking sites are often implemented in HEIs based on the rationale that students, as digital natives, use these tools in their everyday lives. However, Web 2.o has larger implications that go beyond specific tools and applications. The accessibility of these tools that encourage creativity, knowledge creation, conversation, and collaboration has created a student population with a variety of expectations about their learning process and knowledge creation. It becomes fundamentally essential for pedagogy to embrace different approaches to teaching and learning in order to take advantage of the potential of digital media and Web 2.0 applications. Changing student realities mean that pedagogy needs to adjust to student Web habits to maintain the wide variety of contexts in which students accomplish formal and informal learning (Hicks and Graber 2010).

\subsection{Benefits LIS students derive from the use of Web 2.0 technologies}

A Likert scale with choices ranging from strongly agree to strongly disagree was used to ascertain how participants felt regarding the benefits of Web 2.0 technologies (see Table 2). 
Table 2: Benefits of Web 2.0 technologies to LIS students

\begin{tabular}{|l|l|l|l|l|l|}
\hline $\begin{array}{l}\text { Benefit of Web 2.0 technologies to } \\
\text { LIS students }\end{array}$ & $\begin{array}{l}\text { Strongly } \\
\text { agree }\end{array}$ & Agree & Neutral & Disagree & $\begin{array}{l}\text { Strongly } \\
\text { disagree }\end{array}$ \\
\hline $\begin{array}{l}\text { They help me improve technology } \\
\text { proficiency }\end{array}$ & $32.9 \%$ & $56.5 \%$ & $7.1 \%$ & $2.3 \%$ & $1.2 \%$ \\
\hline $\begin{array}{l}\text { Web 2.0 technologies extend beyond } \\
\text { classroom }\end{array}$ & $68.2 \%$ & $21.2 \%$ & $10.6 \%$ & $0 \%$ & $0 \%$ \\
\hline $\begin{array}{l}\text { Web 2.0 technologies provide a } \\
\text { platform for entertainment }\end{array}$ & $9.4 \%$ & $87.1 \%$ & $0 \%$ & $3.5 \%$ & $0 \%$ \\
\hline $\begin{array}{l}\text { They facilitate collaborative learning } \\
\text { Improved knowledge sharing and } \\
\text { collaboration }\end{array}$ & $28.2 \%$ & $68 \% .2 \%$ & $0 \%$ & $3.6 \%$ & $0 \%$ \\
\hline $\begin{array}{l}\text { Provide cheaper and efficient } \\
\text { communication platforms }\end{array}$ & $61.2 \%$ & $36.4 \%$ & $2.4 \%$ & $0 \%$ & $0 \%$ \\
\hline $\begin{array}{l}\text { Useful for safe and secure storage } \\
\text { of documents e.g. Google Docs and } \\
\text { Dropbox }\end{array}$ & $21.2 \%$ & $57.6 \%$ & $10.6 \%$ & $7.1 \%$ & $3.5 \%$ \\
\hline
\end{tabular}

\begin{tabular}{|l|l|l|l|l|l|}
\hline $\begin{array}{l}\text { Benefit of Web 2.0 technologies to } \\
\text { LIS students }\end{array}$ & $\begin{array}{l}\text { Strongly } \\
\text { agree }\end{array}$ & Agree & Neutral & Disagree & $\begin{array}{l}\text { Strongly } \\
\text { disagree }\end{array}$ \\
\hline $\begin{array}{l}\text { Provide easier and faster access to } \\
\text { information, when and where it is } \\
\text { needed }\end{array}$ & $25 \%$ & $68.6 \%$ & $4.4 \%$ & $2 \%$ & $0 \%$ \\
\hline $\begin{array}{l}\text { A low level of complexity is needed } \\
\text { to use Web 2.0 technologies } \\
\text { (minimum skills) }\end{array}$ & $21.3 \%$ & $71.8 \%$ & $2.3 \%$ & $2.3 \%$ & $2.3 \%$ \\
\hline
\end{tabular}

Between 89.4 and 96.5 per cent of the LIS students agreed/strongly agreed that Web 2.0 technologies play a significant role in improving technology proficiency and at the same time having the ability to extend learning beyond the classroom. Web 2.0 technologies also provide a platform for entertainment, facilitate collaborative learning and lead to improved knowledge sharing and collaboration, provide cheaper and efficient communication platforms, allow for easier and faster access to information when and where it is needed. A low level of complexity is needed to use Web 2.0 technologies. Seventy-eight per cent of the LIS students also agreed/strongly agreed that Web 2.0 technologies are useful for safe and secure storage of documents, for example Google Docs.

There is a consensus among various studies that Web 2.0 technologies facilitate communication and collaboration amongst students both in class and online. Web 2.0 technologies have the ability to support active and social learning, provide opportunities and 
venues for student publication, and provide opportunities to provide effective and efficient feedback to students (Ajjan and Hartshorne 2008, 74). Web 2.0 technologies help students to develop more independent learning skills and confidence and become co-producers of knowledge and content (Schroeder and Greenbowe 2009). Web 2.o has the potential to create more interactive and powerful learning environments in which learners become knowledge creators, producers, editors, and evaluators (Richardson 2010; Yuen, Yaoyuneyong and Yuen 2011, 110). In the words of An, Aworuwa, Ballard and Williams (2009, 1), Web 2.0 provides numerous opportunities for social interactions and collaboration among students, teachers, subject matter experts, professionals in different fields, as well as a host of others with related interests.

The benefits of Web 2.0 technologies highlighted the by LIS students are mentioned by many researchers. Web 2.0 has the potential to provide more interactive and customized learning environments where students create knowledge, interact and collaborate with those who have similar interests globally, and obtain opportunities to learn to become professionals in communities of practise, rather than passively receive information from instructors (An et al. 2009, 4).

All six LIS academics interviewed endorsed the fact that Web 2.0 technologies do come with huge benefits. Two of the LIS academics mentioned that Web 2.0 technologies promote communities of practice while at the same time promoting information sharing and collaboration. Web 2.0 technologies, according to the LIS academics, are also easy to use so that users can actually learn on their own. They provide for real time information sharing and are fairly cheap.

Many students in South Africa are obsessed with social media and are almost unanimous that it enhances both their academic and social lives. This was a key finding of the South African High-tech Student 2013 research study, released by World Wide Worx and Student Brands (2013). Web 2.0 tools have a number of affordances which can transform the learning environment by providing multiple opportunities for shared content and resources, self-directed learning, collaborative learning, ubiquitous, low cost, accessibility and lifelong learning. Web 2.0 technologies afford users the opportunity to engage in informal conversations and reflexive dialogue which will expose them to a wide range of ideas and collaborative content generation (Ajjan and Hartshorne 2008, 74; Jimoyiannis, Tsiotakis, Roussinos and Siorenta 2013, 250; NMC Horizon Report 2014, 8).

\subsection{Web 2.o technologies on which LIS students receive instruction}

Over 50 per cent of the LIS students indicated that they received instruction on the use of blogs, Twitter and YouTube. About a third pointed out that they were taught to use wikis and Google Apps but less than 10 per cent stated that they had received training in the use of Delicious, RSS feeds and podcasts (see Figure 3). 
Matingwina $(2014,61)$ explains that Web 2.0 technologies are popular with university students due to their flexibility and social nature. These technologies have proven to be an advantage over the traditional Web (Web 1.0: the static Web) due to their ubiquitous access, low cost, ease of use and functionality. However, Jimoyiannis et al. (2013, 248) mention that, while students are increasingly using new generation technologies such as social networks, text messaging, media sharing, blogs, wikis, and other Web 2.0 applications to communicate and collaborate, this is not the case for many educators. Al-Daihani $(2009,52)$, however, believes that the effective use of Web 2.0 applications is dependent on academics' familiarity and interaction with these tools, the opportunities they have had for exposure to the applications and their level of skills.

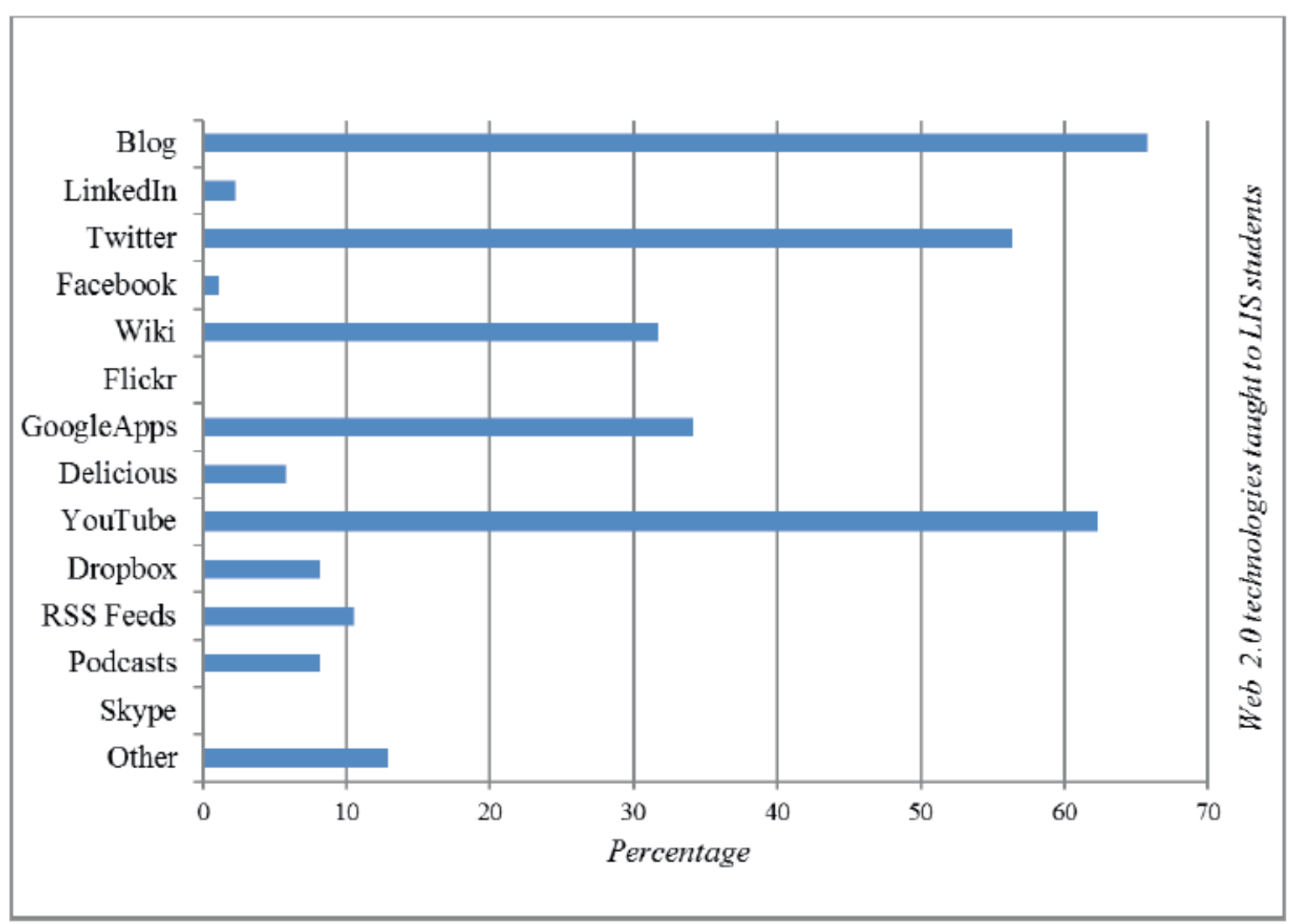

Figure 3: Web 2.0 technologies on which LIS students receive instruction

\section{CONCLUSION AND RECOMMENDATIONS}

It is important to highlight that Web 2.0 should not be viewed as only a technology; it offers many more possibilities (Hicks and Graber 2010). In the words of Virkus (2008, 272), Web 2.0 has impacted the way in which people learn, access information and communicate with each other. To succeed in this era, LIS educators should embrace new ICTs and consider the learning preferences of digital natives as well as digital immigrants. The current research has clearly demonstrated that LIS students are familiar with, and do use, Web 2.0 technologies. The leading Web 2.0 technologies used by LIS students are Facebook, 
WhatsApp, Google Apps, YouTube and Twitter and they use these tools for both academic and general reasons.

Many affordances of Web 2.0 technologies, for example: the ability to collaborate and communicate with peers and academics; their low cost and ease of use; as well as the provision to learn outside the classroom, were some of the highlighted benefits LIS students derive from using Web 2.0 technologies. It is an acceptable notion that Web 2.0 applications have already been adopted by the younger generations as a platform to socialise, collaborate and learn in an informal and flexible manner, although their level of participation varies considerably. To be successful in today's modern society, recognized library associations around the world and LIS educators should work together to ensure that the LIS curriculum is tailored to meet the demands of the ever-changing market.

Web 2.0 is not only required to be an integral part of the LIS curricula, but it should be applied in the structure of the educational context to support both LIS teaching and learning. To achieve this, the following recommendations are made in the light of the study findings:

Although students and lecturers have adopted some Web 2.0 technologies, the research has revealed that a good number of Web 2.0 technologies that could be equally useful for academic purposes are yet to be adopted. Therefore, it is imperative for LIS academics to embed, where possible, a variety of Web 2.0 technologies in the various modules they teach. This could be either in pedagogy, assignments or assessments.

The fact that technology is ever-evolving has a direct bearing on library practices and subsequently on LIS education. As a result, LIS schools have to periodically undergo the rigorous work of curriculum revision and in the process try to keep pace with technological innovations.

LIS schools must fulfil their role of harnessing the potential of emerging technologies to provide more open access to information for people inside and outside their walls as prescribed by the South African Library and Information Services Charter (DAC and NCLIS 2014). 


\section{REFERENCES}

Aharony, N. 2009. "The Influence of LIS Students' Personality Characteristics on Their Perceptions

Towards Web 2.o Use." Journal of Librarianship and Information Science 41 (4): 227-242.

Ajjan, H., and R. Hartshorne. 2008. "Investigating Faculty Decisions to Adopt Web 2.0 Technologies: Theory and Empirical Tests." The Internet and Higher Education 11 (2): 7180 .

ALA (American Library Association). 2013. "Draft Revised Standards for Accreditation of Master's Programs in Library and Information Studies." Committee on Accreditation of the American Library Association. http://www.ala.org/accreditedprograms/sites/ala.org.accreditedprograms/files/content/ standards/Standards_Draft_for_comment_for_RELEASE.pdf (accessed December 30, 2016).

Al-Daihani, S. 2009. "The Knowledge of Web 2.0 by Library and Information Science Academics." Education for Information 27 (1): 39-55.

An, Y. J., B. Aworuwa, G. Ballard, and K. Williams. 2009. "Teaching with Web 2.0 Technologies: Benefits, Barriers and Best Practices." http://www.aect.org/pdf/proceedingso9/2009/09_1.pdf (accessed December 30, 2016).

An, Y. J., and K. Williams. 2010. "Teaching with Web 2.o Technologies: Benefits, Barriers, and Lessons Learned." International Journal of Instructional Technology and Distance Learning 7 (3): 41-48.

Barnet, L., E. Collis, J. Narborough, F. Parry, C. Peel, C. Shields, R. Stubbings, and W. Walton. 2010. "Use of Web 2.0 Tools by Students at Loughborough University." http://www.lboro.ac.uk/media/www/

lboroacuk/library/downloads/surveyresults/Web2.otools.pdf (accessed April 27, 2014).

Bawden, D., L. Robinson, J. Anderson, J. Bates, U. Rutkauskiene, and P. Vilar. 2007. "Towards Curriculum 2.0: Library/Information Education for a Web 2.0 World." Library and Information Research $31 \quad$ (99):

http://www.lirgjournal.org.uk/lir/ojs/index.php/lir/article/view/49 (accessed December 30, 2016).

Blumer, J. G., and E. Katz. 1974. The Uses of Mass Communications: Current Perspectives on Gratifications Research. Beverly Hills: Sage.

Chow, A. S., T. L. Shaw, D. Gwynn, D. Martensen, and M. Howard. 2011. "Changing Times and Requirements: Implications for LIS Education." Library and Information Science 
Research Electronic Journal 21 (1): 2-20. http://www.libres-ejournal.info/wpcontent/uploads/2014/o6/Vol21_I1_Chow_

Shaw_Gwynn_Martensen_Howard_REF_LIBRES21n1.pdf (accessed December 30, 2016).

Chu, H. 2006. "Curricula of LIS Programs in the USA: A Content Analysis." In Proceedings of the Asia- Pacific Conference on Library \& Information Education \& Practice (A-LIEP), Singapore, April 3-6, 328-337. http://hdl.handle.net/10150/105144 (accessed December 30, 2016).

Chua, A. Y. K., and D. H, Goh. 2010. "A Study of Web 2.o Applications in Library Websites." Library and Information Science Research 32 (3): 203-211.

Combes, B., J. Hanisch, M. Carroll, H, Hughes, and A. Millington. 2011. "Are We There Yet? Students Have Their Say About Library and Information Science Education in Australia and Twenty-First Century Learning." IASL Conference Reports, 1-11.

Covili, J. 2012. Going Google: Powerful Tools for 21st Century Learning. London: Sage.

DAC (Department of Arts and Culture) and NCLIS (National Council for Library and Information Services). 2014. "Library and Information Services Transformation Charter." 2014. Pretoria: DAC and NCLIS. http://www.nlsa.ac.za/Downloads_01/2014_Final_LIS_Transformation_Charter.pdf (accessed December 22, 2016).

De Vargas, L. S., M. V. S. De Lara, R. Gonçalves, B. S. Das Neves, and B. P. Mello-Carpes. 2014. "The Use of Facebook as a Tool to Increase the Interest of Undergraduate Students in Physiology in an Interdisciplinary Way." Advances in Physiology Education 38 (3): 273-276.

Eighmey, J., and L. McCord. 1998. "Adding Value in the Information Age: Uses and Gratifications of Sites on the World Wide Web." Journal of Business Research 41 (3): 187194.

Foo, S., and J. Ng. 2008. "Library 2.0, Libraries and Library School." Paper presented at the Library Association of Singapore Conference, Singapore, May 8-9. http://www.ntu.edu.sg/home/sfoo/ publications/2008/2008LAS-SF-JN_fmt.pdf (accessed December 22, 2016).

Garoufallou, E., and V. Charitopoulou. 2011. "The Use and Awareness of Web 2.0 Tools by Greek LIS Students.” New Library World 112 (12): 490-498.

Garoufallou, E., and V. Charitopoulou. 2012. "Web 2.0 in Library and Information Science Education: The Greek Case.” New Library World 113 (3/4): 202-217. 
Harris, A. L., and A. Rea. 2009. "Web 2.0 and Virtual World Technologies: A Growing Impact on IS Education.” Journal of Information Systems Education 20 (2): 137-144.

Hicks, A., and A. Graber. 2010. "Shifting Paradigms: Teaching, Learning and Web 2.o." Reference Services Review 38 (4): 621-633.

Huang, E. 2008. "Use and Gratification in e-Consumers." Internet Research 18 (4): 405-426.

IFLA (International Federation of Library Associations and Institutions). 2012. "Guidelines for Professional Library/Information http://www.ifla.org/publications/guidelines-forEducational Programs." educational-programs-2012 (accessed 12 March 2014).

Jimoyiannis, A., P. Tsiotakis, D. Roussinos, and A. Siorenta. 2013. "Preparing Teachers to Integrate Web

2.0 in School Practice: Towards a Framework for Pedagogy 2.0." Australasian Journal of $\begin{array}{lllll}\text { Educational } & \text { Technology } & 29 & \text { (2): } & \text { 248-267. }\end{array}$ http://ascilite.org.au/ajet/submission/index.php/AJET/article/view/ 157/ 55 (accessed December 22, 2016).

Maloney, E. 2007. "What Web 2.0 Can Teach us About Learning." Chronicle of Higher Education 25 (18): B26.

Matingwina, T. 2014. "Knowledge, Attitudes and Practices of University Students on Web 2.o Tools: Implications for Academic Libraries in Zimbabwe." Zimbabwe Journal of Science and Technology 9 (6): 59-72. http://www.nust.ac.zw/zjst/index.php/volume-9-2014\# (accessed December 16, 2016).

Mishra, S. 2009. "Social Networking Technologies (SiTS) in Digital Environment: Its Possible Implications on Libraries." http://eprints.rclis.org/16844/1/Social\%2onetworking\%20in\%2oLibrary.pdf (accessed December 19, 2016).

Murugesan, S. 2007. "Understanding Web 2.o." https://91-592722.wiki.uml.edu/file/view/understanding _ web_20.pdf (accessed December 18, 2016).

Nagatsuka, T., H. Tsunoda, and T. Harada. 2013. "The Improvements in Quality of LIS Education Through the Mutual International Exchange of Students in the East Asia." http://library.ifla.org/155/1/199- nagatsuka-en.pdf (accessed December 18, 2016).

NMC Horizon Report. 2014. "Higher Education Edition." http://cdn.nmc.org/media/2014nmc-horizon- report-he-EN-SC.pdf (accessed December 18, 2016). 
Noh, Y., I. Ahn, and S. Choi. 2012. "A Study of Changes in the Library and Information Science Curriculum with Evaluation of Its Practicality." Journal of Academic Librarianship 38 (6): $348-364$.

Ocholla, D., and T. Bothma. 2007. "Library and Information Education and Training in South $\begin{array}{lllll}\text { Africa." New Library } 108 \quad \text { World } & \text { (2): } & \text { 149-169. }\end{array}$ http://dx.doi.org/10.1108/03074800710722180

Raju, R. 2005. "LIS Education and Training in South Africa: A Historical Review." South African Journal of Libraries and Information Science 71 (1): 74-84.

Raju, R. 2013. "The LIS School in the ICT Age: A Casualty, or a Catalyst for a Paradigm Shift? The Case of South Africa." http://library.ifla.org/177/1/199-raju-en.pdf (accessed December 18, 2016). Richardson, W. 2010. Blogs, Wikis, Podcasts and Other Powerful Web Tools for Classrooms. Third edition.

London: Corwin.

Ruggiero, T. E. 2000. "Uses and Gratifications Theory in the 21st Century." Mass Communication and Society 3 (1): 3-37.

Sarrafzadeh, M., A. Hazeri, and S. Alavi. 2011. "The Status of Web 2.0 in Iran's LIS Education." Education for Information 28 (2): 233-245.

Sawant, S. 2012. "The Study of the Use of Web 2.0 Tools in LIS Education in India." Library Hi Tech News 12 (2): 11-15.

Schroeder, J. and T. J. Greenbowe. 2009. "The Chemistry of Facebook: Using Social Networking to Create an Online Community for the Organic Chemistry Laboratory." Innovate: Journal of Online Education 5 (4): 1-7.

Shao, G. 2009. "Understanding the Appeal of User-Generated Media: A Uses and Gratification Perspective."

Internet Research 19 (1): 7-25. http://dx.doi.org/10.1108/10662240910927795

Srivastava, R. 2009. "Web 2.0 in LIS Curriculum: A Preliminary Study." Paper presented at the 7th International CALIBER, Pondicherry University, Puducherry, February 25-27. http://www.inflibnet. ac.in/caliber2009/CaliberPDF/47.pdf (accessed December 17, 2016).

Stafford, T. F., and L. Schkade. 2004. "Determining Uses and Gratifications for Internet." Decision Sciences Spring 35 (2): 259-280.

Theimer, K. 2010. Web 2.o Tools and Strategies for Archives and Local History Collections. London: Neal- Schuman. 
Tumuhairwe, G. K. 2013. "Analysis of Library and Information Science/Studies (LIS) Education Today: The Inclusion of Indigenous Knowledge and Multicultural Issues in LIS Curriculum." http://library. ifla.org/276/1/125-tumhuwaire-en.pdf (accessed December 17, 2016).

UCT (University of Cape Town). 2013. "Postgraduate Diploma in Library and Information Studies Course Outline." http://www.lisc.uct.ac.za/sites/default/files/image_tool/images/40/Course-Outline-for2013-Curriculum.pdf (accessed December 22, 2016).

UWC (University of the Western Cape), Department of Library and Information Science. 2015. "Master's in Library and Information Studies." https://sites.google.com/site/mlibinfostudies/home (accessed December 16, 2016).

Virkus, S. 2008. "Use of Web 2.0 Technologies in LIS Education: Experiences at Tallinn University, Estonia.” Program: Electronic Library and Information Systems 42 (3): 262-274. http://dx.doi. org/10.1108/00330330810892677

Wolske, M. 2013. "LIS Education Q and A with Martin Wolske, 2011 LJ Teaching Award Winner." http:// ischool.illinois.edu/articles/2013/o4/wolske-honored-caepe-award (accessed December 22, 2016).

World Wide Worx and Student Brands. 2013. "Social Media: Addiction and Boon to Students." http://www.worldwideworx.com/hightech-students/ (accessed December 16, 2016).

Yuen, S. C. Y., G. Yaoyuneyong, and P. K. Yuen. 2011. "Perceptions, Interest, and Use: Teachers and Web 2.0 Tools in Education." International Journal of Technology in Teaching and Learning 7 (2): 109- 123.

Zaremohzzabieh, Z., S. B. Abu, S. Z. Omar, J. Bolong, and N. A. Kamarudin. 2014. "Addictive Facebook Use Among University Students.” Asian Social Science 10 (6): 107-116. 